\title{
A modernidade e suas sombras: problemas historiográficos no ensino de filosofia
}

Rodrigo Marcos de Jesus ${ }^{1}$

\section{Resumo}

Este artigo analisa a chamada Modernidade (sua periodização, caracterização, seus temas, problemas e filósofos significativos) apontando como seu estudo no ensino superior e no ensino médio apresenta uma historiografia marcada pela colonialidade do saber e pelo eurocentrismo. Propõe, assim, observar alguns problemas historiográficos da filosofia, entender suas causas e buscar ver o que está nas sombras da tradição filosófica.

Palavras-chave: Modernidade. Historiografia. Eurocentrismo.

\section{Resumen}

Este artículo analiza la llamada Modernidad (su periodización, caracterización, sus temas, problemas y filósofos significativos) apuntando como su estudio en la enseñanza superior y en la enseñanza media presenta una historiografía marcada por la colonialidad del saber y el eurocentrismo. Propone, así, observar algunos problemas historiográficos de la filosofía, entender sus causas y buscar ver lo que está en las sombras de la tradición filosófica.

Palabras-clave: Modernidad. Historiografía. Eurocentrismo.

\footnotetext{
${ }^{1}$ Professor Assistente de Filosofia na Universidade Federal de Mato Grosso/UFMT. Email: rodrigomarcosdejesus@yahoo.com.br
} 


\section{O problema do óbvio}

$\mathrm{E}$ ste ensaio nasce de uma preocupação com o ensino de filosofia. A mim assombra cada vez mais a percepção de que a filosofia ensinada nas universidades e nas escolas, transmitida em publicações especializadas ou de cunho didático, apresente uma narrativa histórica muito parecida, a despeito da variedade de abordagens. Existe um certo consenso nos grandes marcos históricos e nos temas, problemas e autores de destaque. É como se - para usar uma analogia musical - houvesse um mesmo tema e suas variações. O tema, nessa comparação, é uma história oficial da filosofia cuja periodização, caracterização e filósofos de relevância permanecem os mesmos, recebendo aqui e ali pequenas variações a depender do intérprete, no caso, do pesquisador ou do professor. Ofereço abaixo indicações do que tem me chamado atenção a partir de um recorte e da reunião de dados gerais recolhidos em distintas fontes. Utilizarei, para fins expositivos, mapas e tabelas ilustrativos.

Figura 1: Mapa-múndi da Filosofia Moderna

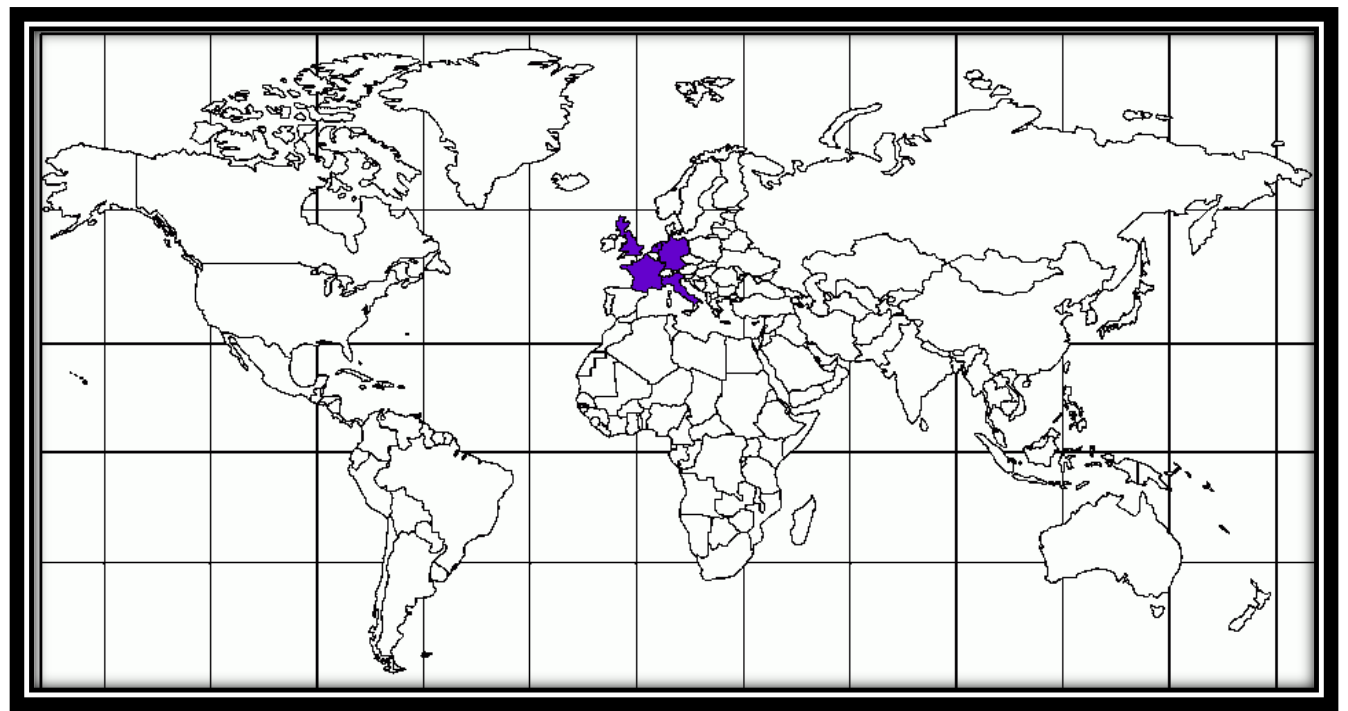

Filos. e Educ., Campinas, SP, v.10, n.1, p.90-120, jan./abr. 2018 - ISSN 1984-9605 
Figura 2: Lista dos Filósofos da Modernidade

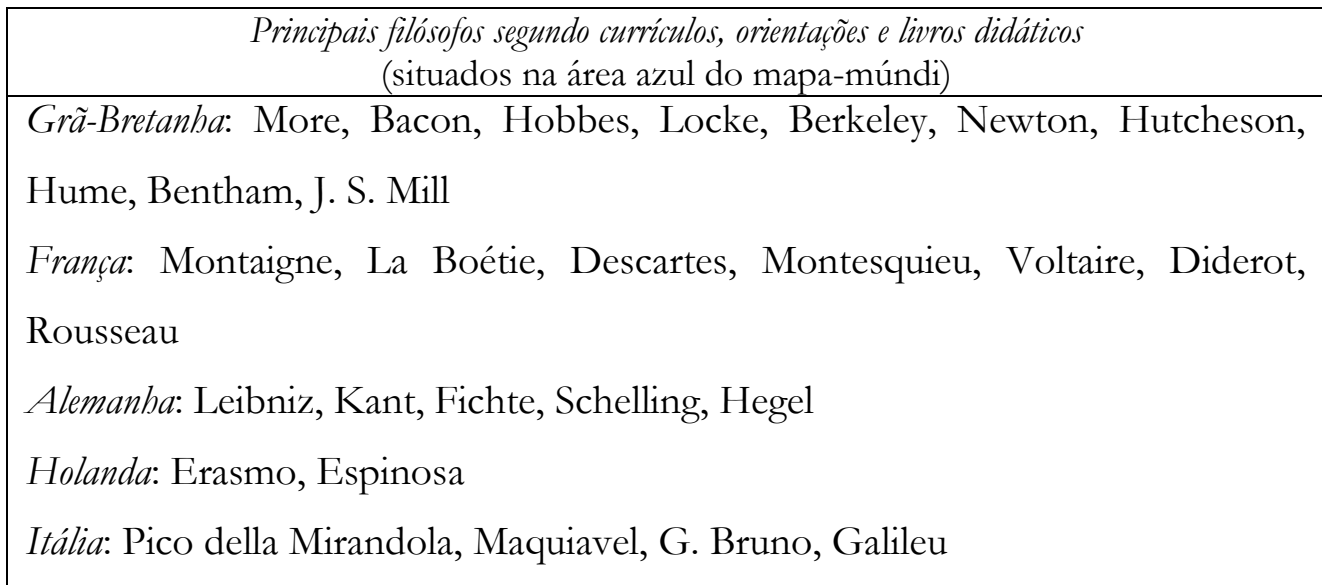

O mapa e a lista foram elaborados a partir de um recorte temporal: a filosofia moderna, incluindo-se o período do Renascimento. Os dados foram recolhidos em três fontes: currículos acadêmicos, orientações curriculares para o ensino médio e livros didáticos. Essas fontes são importantes, pois indicam os principais direcionamentos e disposições do ensino de filosofia, tanto no âmbito acadêmico quanto no escolar. Os currículos e as orientações são balizadores, apontam formas e conteúdos do ensino, apresentam as intenções e propostas de uma disciplina. Os livros didáticos, por sua vez, introduzem e divulgam os conhecimentos produzidos, contribuem para formar certa visão da área de conhecimento, materializam, por assim dizer, as intenções expressas nos currículos e nas orientações. Além disso, tais fontes sancionam, direta ou indiretamente, isto é, por um ato legal ou por um hábito da comunidade de estudiosos, os conhecimentos considerados relevantes, merecedores de serem transmitidos e continuamente revisitados.

Selecionou-se os currículos de 9 cursos de licenciatura em filosofia do país das seguintes instituições: USP, Unicamp, UFSC, UFBA, UFRJ, UFMG, UFRGS, PUC-Rio e UNIFRA (Centro Universitário Franciscano do Rio Grande do Sul). Essa amostra baseou-se em dois critérios a) cursos mais antigos e referências na pesquisa e ensino de filosofia no país ${ }^{2}$ e b) cursos

2 Casos da USP, UFRJ, UFMG, UFRGS, PUC-Rio e UFBA, universidades tradicionais e de reconhecida qualidade, fundadoras do ensino universitário de filosofia no Brasil, com cursos que remontam aos anos 1930 e 1940. 
bem avaliados em rankings internacionais ${ }^{3}$ e pelo $\mathrm{MEC}^{4}$. Na análise dos currículos observou-se basicamente ${ }^{5}$ os conteúdos das ementas e programas de disciplinas obrigatórias constantes nos projetos pedagógicos de curso e/ou disponibilizadas em listas de disciplinas nos sites de cada instituição. Optou-se por investigar as disciplinas ligadas à História da Filosofia Renascentista e/ou Moderna, à Filosofia Política, à Ética e à Antropologia Filosófica $^{6}$. Isso porque essas disciplinas costumam apresentar discussões sobre as características e o sentido da modernidade, resaltando os filósofos fundadores de novos marcos teóricos. Além disso, disciplinas como "Ética" e "Filosofia Política" mostram-se propícias para abordagem de temas fundamentais para o ensino da filosofia como liberdade, democracia, opressão, racismo, tolerância.

Quanto às orientações curriculares, usaram-se as Orientações Curriculares para o Ensino Médio: Filosofia, publicadas em 2006 pelo MEC

${ }^{3}$ Casos de USP (nos anos de 2014, 2015, 2016 e 2017), Unicamp (nos anos de 2014, 2015, 2016 e 2017), UFRGS (nos anos de 2014, 2015 e 2016), UFMG (no ano de 2014) e UFRJ (no ano de 2014) que figuraram entre os 100 melhores cursos de filosofia do mundo segundo o Quacquarelli Symonds $(Q S)$, que se baseia em milhares de questionários respondidos por acadêmicos dos cinco continentes, considerando a reputação acadêmica, empregabilidade dos egressos e citações em artigos científicos dos integrantes das instituições. Informações disponíveis em: https://www.topuniversities.com/universityrankings/university-subject-rankings/2017/philosophy. Acesso em 23/01/2018.

${ }^{4}$ Casos da UNIFRA, UFSC, PUC-Rio e UFRJ que receberem a maior nota (faixa 5) no último Conceito Preliminar de Curso (CPC), de 2014, indicador de qualidade empregado pelo INEP baseado na avaliação de desempenho de estudantes no Enade, no valor agregado pelo processo formativo e em insumos referentes às condições de oferta - corpo docente, infraestrutura e recursos didático-pedagógicos. Informações disponíveis em http://portal.inep.gov.br/conceito-preliminar-de-curso-cpc-. Acesso em 23/01/2018.

${ }^{5}$ Exceção feita à análise do currículo da UFRJ, de caráter mais flexível, com poucas disciplinas obrigatórias e grande rol de disciplinas optativas divididas em três grupos: de escolha restrita e de escolha condicionada, perfazendo as disciplinas filosóficas (a maior parte do currículo), e de escolha livre, disciplinas cursadas fora da filosofia (menor parte do currículo). Assim, buscaram-se as ementas e programas das disciplinas filosóficas (obrigatórias e optativas) de oferta recente. Os dados disponíveis no site do curso permitiram obter informações sobre os anos de 2015 e 2016.

${ }^{6}$ Disciplinas pesquisadas: UFSC (História da Filosofia III; Filosofia Política II; Ética II), PUC-Rio (Antropologia Filosófica I; História da Filosofia Moderna I e II; Ética I), UFRJ (História da Filosofia Moderna I, II, III, IV, V e VI; Ética IV; Antropologia Filosófica II; Seminário de História da Filosofia Moderna II; Filosofia Política III), Unicamp (Ética I, História da Filosofia Moderna I), UFRGS (Ética Moderna; História da Filosofia Moderna I; Filosofia Política; Seminário de Filosofia Política - B), UFMG (Antropologia Filosófica; História da Filosofia Moderna I e II; Seminário em Filosofia Moderna; Ética), USP (História da Filosofia Moderna I e II; Ética e Filosofia Política I), UNIFRA (História da Filosofia Moderna I e II; Ética I e II; Filosofia Política e Social I e II; Antropologia Filosófica), UFBA (História da Filosofia Moderna I e II; Ética I- A; Filosofia Política). 
e atualmente em vigor. Os dois livros didáticos escolhidos para compor o quadro geral da investigação apresentam diferentes perspectivas metodológicas, uma temática (Filosofando: introdução à filosofia, de Maria L. Aranha e Maria H. Martins) e outra problemática (Filosofia: experiência do pensamento, de Sílvio Gallo), e foram ambos selecionados pelo Plano Nacional do Livro Didático - PNLD nos anos de 2015 e 2017, constituindose, portanto, em obras de referência para o ensino de filosofia no país ${ }^{7}$, no nível médio.

Após o recorte e a análise levantou-se a origem e o local de atuação dos filósofos estudados (cf. Figura 2). À primeira vista algo se evidencia, todos os filósofos se concentram em uma região específica do planeta, a saber: a Europa (cf. Figura 1). Porém, se atentarmos mais detidamente, notaremos que nem toda Europa está aí contemplada. A Península Ibérica não traz um único representante, em contrapartida, as regiões central e setentrional do continente acumulam a maior parte dos pensadores. O mapa revela uma curiosa "geografia da razão filosófica". Parece indicar que o que vale a pena ser estudado e ensinado da filosofia moderna encontra-se muito bem situado, diria mesmo demarcado espacialmente. E quais seriam os assuntos debatidos pelos filósofos dessa região e que mereceriam acolhida de acordo com as fontes consultadas? O quadro a seguir lista os tópicos recorrentes ${ }^{8}$, com ênfase nas correntes filosóficas e nos temas.

\footnotetext{
${ }^{7}$ Utilizei-me das edições aprovadas no PNLD de 2015

${ }^{8}$ Registre-se uma exceção. No ano de 2016, a UFRJ ofertou a disciplina "História da Filosofia Moderna V", ministrada pelo professor Luiz A. Cerqueira, estudioso da filosofia brasileira, sendo abordado as doutrinas ético-morais no contexto da escravidão no Brasil a partir das obras de Pe. Vieira, Gonçalves de Magalhães e Tobias Barreto. Esse caso é a exceção que confirma a regra. As características do currículo da UFRJ, aliada ao meritório esforço do prof. Cerqueira através do CEFIB (Centro de Filosofia Brasileira), possibilitam que vez ou outra um tema ou autor diferente do padrão apontado seja objeto de análise filosófica. Acrescente-se, entretanto, que isso não foi observado quando a oferta de disciplinas esteve a cargo dos outros professores do curso de filosofia da instituição.
} 
Figura 3: Temas e correntes

\begin{tabular}{l} 
Lista de temas e correntes \\
\hline Racionalismo, empirismo, ceticismo e criticismo \\
Idealismo alemão (transcendental e absoluto) \\
Republicanismo, Contratualismo, Liberalismo \\
Éticas deontológica (matriz kantiana) e consequencialista (utilitarismo) \\
Revolução científica \\
Renascimento \\
Iluminismo \\
Liberdade, direito e política
\end{tabular}

Depois de ver as figuras acima talvez alguém possa objetar que nada mais se fez do que expor o óbvio: a presença da tradição filosófica moderna nos currículos, na legislação e nos materiais de ensino que, felizmente diria o hipotético interlocutor - , divulgam o pensamento clássico transmitido nos centros de formação docente e prescrito nas leis. Todas essas ilustrações, enfim, não passariam de um dado sem maior relevância. Contudo, é exatamente essa obviedade e a naturalização de uma tradição que, julgo, torna-se interessante e pertinente questionar. Afinal, que acordo tácito parece estar presente nessa construção narrativa? Não haveria algo sendo dito pelos silêncios das terras aparentemente não agraciadas com a luz da filosofia? Será que nosso olhar já não está viciado, adestrado e temos dificuldade em perceber como determinados assuntos, nessa tão conhecida história, nunca ou raramente são explicitados? Em síntese, por que a obviedade dessa tradição, de seus representantes, de seus temas e problemas não costuma ser posta em questão? Como explicar essa curiosa concórdia quanto à história em um campo como o filosófico justamente caracterizado pela diversidade de posições teóricas, muitas vezes inconciliáveis?

A proposta deste trabalho é colocar o óbvio (a história da filosofia, a tradição filosófica) como problema. Para isso, tomarei como objeto de análise a chamada Modernidade (sua periodização, caracterização, seus temas, problemas e filósofos significativos). Indicarei como seu estudo no 
ensino superior e no ensino médio apresenta uma historiografia marcada pela colonialidade do saber e pelo eurocentrismo. Essa formulação pode soar estranha aos ouvidos não acostumados com os termos do debate, por isso tratarei de definir sumariamente os termos "colonialidade", "colonialidade do saber" e "eurocentrismo". Tais conceitos permitirão - eis a aposta - observar alguns problemas historiográficos da filosofia, entender as causas desses problemas e buscar ver o que está nas sombras, nos espaços aparentemente incógnitos da tradição filosófica. A exposição será mais sugestiva que exaustiva; detalhar todos os passos da discussão nos levaria longe. Espero, contudo, que os principais problemas e argumentos fiquem suficientemente bem colocados e permitam uma compreensão global das questões propostas.

\section{Colonialidade e Eurocentrismo: aporte teórico}

A modernidade, no seu aspecto histórico-conceitual, é comumente apresentada no ensino de filosofia como uma época nova do pensamento ocidental, em contraste com a Idade Média, tendo como acontecimentos históricos, culturais, políticos e econômicos mais significativos o Renascimento, a Reforma Protestante, a descoberta do Novo Mundo, o capitalismo e a ascensão da burguesia, a Revolução Científica, as Revoluções inglesas do séc. XVII, a Independência dos EUA ${ }^{9}$, a Revolução Industrial, o Iluminismo e a Revolução Francesa. O período abarcado vai dos séculos XV ao XVIII, com alguma variação dependendo do enfoque. Estudiosos, principalmente de Itália, Espanha e Portugal, remontam ao Renascimento e às Grandes Navegações, já alemães, ingleses e franceses costumam destacar o Iluminismo e as revoluções políticas dos séculos XVII e XVIII. Contudo, nenhum desses dois grupos deixa de reconhecer a importância dos acontecimentos acima apontados para a constituição do

\footnotetext{
${ }^{9} \mathrm{O}$ caso da Independência dos EUA é interessante. Apesar de ocorrer em um contexto americano é visto como expressão de aspirações nascidas na Europa, como o Iluminismo e o liberalismo. Logo, não causa estranheza ser esse acontecimento um dos marcos políticos da tradição ocidental, que no decorrer do século XX ganha uma feição euro-norteamericana.
} 
mundo moderno. E quando se indicam os filósofos que melhor expressariam, em toda sua singularidade, uma nova perspectiva de pensamento, os nomes de Descartes e Bacon despontam como símbolos da filosofia moderna, instituidores das duas correntes filosóficas principais do período - racionalismo e empirismo - que viriam a se articular posteriormente no criticismo de Kant e no idealismo. Já as dimensões éticas e políticas da modernidade caracterizam-se pela valorização do indivíduo e sua liberdade frente às opressões políticas (o contratualismo), às restrições econômicas (liberalismo), ao cerceamento da inteligência e das artes (Renascimento, Revolução científica, Iluminismo) e à experiência religiosa (o protestantismo). Essa narrativa geral e suas expressões filosóficas apresentam um tom de progresso, de emancipação do indivíduo e da sociedade desde um horizonte europeu que se desenvolve material e culturalmente de maneira autônoma, deixando para traz, ainda que de modo conturbado, estruturas sociais e políticas rígidas e hierarquizadas e formas tuteladas de pensar. Os discursos filosóficos produzidos ou prepararam ou valorizam uma liberdade de ação e de pensamento dirigidos a toda humanidade, sem distinção. As ideias possuem, nesse sentido, uma validade universal. Aquilo que soa como retrógrado, seja pelo seu estilo, forma ou conteúdo tende a desaparecer no decorrer do desenvolvimento histórico.

Essa visão, aqui exposta em traços largos, possui detalhes curiosos. Três chamam a atenção. Primeiro, a América Latina, mesmo sendo um fator histórico de destaque no início da modernidade, dada a chamada “descoberta do Novo Mundo", parece não ter tido maior relevância do ponto de vista filosófico. Salvo uma ou outra referência ao texto "Os canibais", contido nos Ensaios de Montaigne, não há maiores indicações nos currículos e livros didáticos sobre possíveis impactos dessa "descoberta" na consciência filosófica da época ou mesmo alguma reflexão acerca das questões éticas e políticas da colonização. Segundo, como já assinalado no tópico introdutório, não se faz referência a autores da Península Ibérica, região que no século XVI despontava política e economicamente no contexto europeu. Isso indicaria uma espécie de atraso filosófico-cultural da 
região? Será que Espanha e Portugal, primeiros impérios de proporções mundiais, primeiros povos europeus a entrar em contato e colonizar territórios e populações completamente desconhecidas para a Europa não produziram contribuições filosóficas a partir desse fato radicalmente novo na história mundial? Terceiro, estranhamente nada se diz - de forma explícita nos currículos ou nos livros didáticos - sobre a colonização, a escravidão ou o racismo. Tais assuntos estão ausentes mesmo em programas de disciplinas com um corte mais histórico, assim como nos livros ao debaterem temas e problemas relacionados à ética e à política. Fica a impressão de que os filósofos ou não trataram dessas matérias ou as discutiram de forma bastante geral ao lidarem com os problemas da liberdade política. Mas pensando um pouco mais, será que, por acaso, algum dos filósofos mais celebrados contribuiu com suas ideias - quiçá suas práticas - para justificar o domínio sobre terras e povos não-europeus? Ensina-se filosofia política e ética de autores dos séculos XVI a XVIII e nenhum deles teria opinião sobre esses assuntos?

Esses três pontos, dentre outros, não passaram despercebidos por autores latino-americanos estudiosos do período moderno e de sua filosofia. De acordo com o grupo de investigadores vinculados à filosofia da libertação e ao pensamento decolonial, desde a perspectiva das ex-colônias portuguesas e espanholas da América, não se compreende a modernidade sem a colonialidade. Quer dizer: o progresso da modernidade está constitutivamente associado à violência colonial. Esse é um modelo interpretativo que modifica substancialmente nossa compreensão dessa época, uma vez que propõe conceber a história moderna a partir da interrelação entre a Europa e o mundo não-europeu e o conceito de modernidade através da chamada lógica da colonialidade. Em síntese, implica considerar como aspecto constitutivo da modernidade - e não meramente aditivo ou ideológico - a colonialidade, nas suas dimensões econômica, política, social, cultural e epistêmica. Nesse sentido, quando olhamos para a era moderna, descrevendo seus elementos históricos e suas ideias filosóficas, precisamos estar atentos não apenas ao que é considerado moderno pelas 
narrativas comuns (em resumo, o exposto no início deste tópico) mas também o que é visto como não pertencente propriamente à modernidade, pois julgado como resquício de um tempo anterior ou como uma espécie de efeito colateral indesejado (a exemplo do colonialismo, da dependência econômica e do racismo) porém superável por meio do desenvolvimento das forças e ideais modernizantes. Filósofos e pensadores latino-americanos, assim, põem em xeque concepções que dissociam o desenvolvimento político, econômico e cultural europeu da exploração colonial, o discurso humanista universalista da elaboração de categorias sociais estratificadoras, o ideal de liberdade da defesa da escravidão, a ordenação jurídica da arbitrariedade legal, a constituição do eu da negação do outro.

Pretende-se fazer a crítica a um pretenso "ponto zero de observação", segundo o qual, aquilo que se compreende como mundo moderno seria o mesmo independentemente do local de onde se narra história. Local tanto do ponto de vista social (algo já apontado por outras tradições críticas como o marxismo e a escola de Frankfurt) quanto geográfico. Situar-se epistemicamente em outras partes do mundo, isto é, olhar um dado fenômeno consciente de sua localização geopolítica abre a possibilidade de ler, reler e interpretar o mundo desde um "conhecimento outro". Não se trata de substituir uma forma de conhecimento hegemônica por outra tida mais verdadeira. A ideia é menos ambiciosa e mais desafiadora: pluralizar os modos de conhecimento e as narrativas sobre o mundo como forma de aumentar a inteligibilidade das coisas, reconhecer a inevitável parcialidade de nossos saberes e se contrapor aos projetos homogeneizantes de saber e de poder. Afinal, os modos de dominação sobre ideias, pessoas e territórios não se encontram separados.

Convém, portanto, conforme Mihnolo (2007, p. 36), considerar a 'modernidade/colonialidade' como duas caras de uma
mesma moeda e não como duas formas de pensamento
separadas: não se pode ser moderno sem ser colonial, e
se um se encontra no extremo colonial do espectro, deve
negociar com a modernidade, pois é impossível passá-la
por alto. 
A modernidade caminha com a colonialidade. Este termo, para bem da clareza, não deve ser confundido com colonialismo, ainda que possua vínculos. O colonialismo, segundo Quijano, "refere-se estritamente às estruturas de dominação/exploração onde o controle da autoridade política, dos recursos de produção e do trabalho de uma população determinada domina outra de diferente identidade e cujas redes centrais estão, além disso, localizadas noutra jurisdição" (2010, p. 84, nota 1). O colonialismo é mais antigo que a colonialidade. Esta origina-se e mundializa-se a partir da conquista e exploração da América, implica relações racistas de poder, associa-se à modernidade como seu lado obscuro e é mais profunda e duradoura que o colonialismo. A colonialidade, assim, é uma estrutura complexa e entrelaçada em distintos níveis, reproduzindo-se nas dimensões do poder, do saber e do ser.

A perspectiva que destaca as dimensões da colonialidade, de acordo com Mignolo (2007), pode ser sintetizada nessas premissas básicas.

1. Não existe modernidade sem colonialidade, já que esta é parte indispensável da modernidade.

2. O mundo moderno/colonial (e a matriz colonial de poder) se origina no século XVI, e o descobrimento/invenção da América é o componente colonial da modernidade cuja cara visível é o Renascimento europeu.

3. A Ilustração e a Revolução Industrial são momentos históricos derivados que consistem na transformação da matriz colonial de poder.

4. A modernidade é o nome do processo histórico em que a Europa iniciou o caminho para a hegemonia. Seu lado obscuro é a colonialidade.

5. O capitalismo, tal como o conhecemos, está na essência da noção de modernidade e de seu lado obscuro, a colonialidade.

6. O capitalismo e a modernidade/colonialidade tiveram um segundo momento histórico de transformação depois da Segunda Guerra Mundial, quando os Estados Unidos se apropriaram da liderança 
imperial de que antes haviam gozado, em distintas épocas, Espanha e Inglaterra.

A partir dessas premissas pode-se colocar o ensino de filosofia numa perspectiva descolonizadora que detectará as marcas coloniais do seu saber. Desse modo, a filosofia moderna estudada se revela apenas um lado da moeda filosófica, aquele centrado na Europa, ou melhor, em uma parte do continente, e que expõe o lado luminoso da modernidade. As ideias filosóficas (de ambos os lados da moeda) e os filósofos mais expressivos do outro lado permanecem nas sombras e invisíveis no mapa filosófico (cf. novamente a figura 1). Para sair dessa visão parcial é necessária a crítica da colonialidade do saber e de uma das suas características principais, o eurocentrismo.

A colonialidade do saber "suporia uma espécie de arrogância epistêmica por aqueles que se imaginam modernos e se consideram possuidores dos meios mais adequados (ou inclusive únicos) de acesso à verdade (seja esta teológica ou secularizada) e, portanto, supõem que podem manipular o mundo natural ou social segundo seus próprios interesses" (RESTREPO e ROJAS, 2010, p. 135, tradução própria). Desse modo, outras formas de conhecimento, em geral associadas às populações não-europeias, são negadas, menosprezadas ou ignoradas. Como consequência, as modalidades de conhecimento (científico, teológico, filosófico) consideradas válidas, verdadeiras, rigorosas são aquelas propriamente europeias. Essa hegemonia do modo eurocêntrico de percepção e produção de conhecimento teve estreita ligação com o domínio europeu sobre territórios e povos e, como salienta Quijano (2010), “numa parte muito ampla da população mundial o próprio imaginário foi, demonstradamente, colonizado". Sendo assim, o eurocentrismo não pode ser visto apenas como uma exclusividade cognitiva dos europeus ou dos países centrais do capitalismo mundial, uma vez que está também presente nos países, nas instituições e nos povos que sofreram sua hegemonia. A filosofia, por conseguinte, não estaria isenta dessa influência. 
Mas como o eurocentrismo está presente na filosofia? O mapa e as tabelas deste ensaio apontaram a "geografia da razão filosófica" circunscrita a uma parte da Europa, cabe agora especificar melhor o eurocentrismo a fim de entender sua dinâmica. As reflexões do filósofo argentino-mexicano Enrique Dussel auxiliam nessa tarefa.

De acordo com DUSSEL, “O 'eurocentrismo' da Modernidade é exatamente a confusão entre universalidade abstrata com a mundialidade concreta hegemonizada pela Europa como “centro"” (2005, p. 5). Quer dizer, a concepção de mundo que coloca os conhecimentos, as instituições, as formas sociais, os valores produzidos pela Europa como referência e padrão de desenvolvimento, de civilização, de cultura para as outras regiões do planeta é antes o resultado de uma mudança nas relações de poder no mundo que o resultado puro da maturidade da razão, do esforço de uma conquista espiritual. Por isso, ignorar a complexidade da trama histórica que permitiu a Europa se tornar, durante a modernidade, o centro político-econômicomilitar-cultural do mundo é cair na confusão, na identificação simplista entre "universalidade abstrata" e "mundialidade concreta". Daí que, do ponto de vista do ensino de filosofia, conceber a narrativa usual da história da filosofia moderna (seus marcos, suas caracterizações, seus autores) como a expressão pura e simples da universalidade filosófica é desconsiderar as relações de poder que possibilitaram tornar tal narrativa, e não outra, a história oficial da filosofia moderna, aquela que merece ser pesquisada, ensinada, divulgada.

Dussel destaca dois paradigmas de modernidade: um eurocêntrico e um mundial. O primeiro compreende a modernidade como "uma emancipação, uma 'saída' da imaturidade por um esforço da razão como processo crítico, que proporciona à humanidade um novo desenvolvimento do ser humano. Este processo ocorreria na Europa, essencialmente no século XVIII” (2005, p. 4). Esse paradigma sublinha o autodesenvolvimento da consciência europeia, sua capacidade, a partir de um trabalho interno, de uma maturação intelectual que começaria a ganhar seus contornos no período renascentista, mas remontaria a uma longa tradição desde a 
Antiguidade Greco-romana. Seria, então, possível reconstituir a trajetória histórica desse desenvolvimento em suas grandes fases, saindo da Grécia antiga e culminando, no século XVIII, no Iluminismo. O esquema abaixo ilustra os passos dessa pretensa sequência histórica.

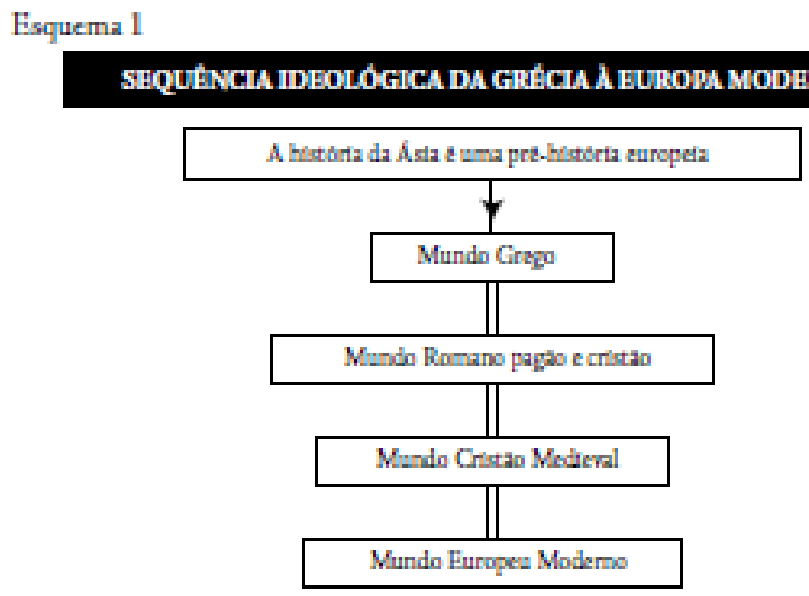

O segundo paradigma adota uma outra visão do processo histórico. A Europa não é o ponto culminante da história, não há, portanto, uma linearidade. A modernidade, numa perspectiva mundial,

[...] consistiria em definir como determinação fundamental do mundo moderno o fato de ser (seus [europeus] Estados, exércitos, economia, filosofia, etc.) 'centro' da História Mundial. Ou seja, empiricamente nunca houve História Mundial até 1492 (como data de início da operação do 'Sistema-mundo'). Antes dessa data, os impérios ou sistemas culturais coexistiam entre si. Apenas com a expansão portuguesa desde o século $\mathrm{XV}$, que atinge o extremo oriente no século XVI, e com o descobrimento da América hispânica, todo o planeta se torna o 'lugar' de 'uma só' História Mundial (DUSSEL, 2005, p. 4).

Isso significa que a hegemonia, a centralidade conseguida pelo pensamento europeu ocorre no momento em que a Europa passa a ser centro político-econômico-militar do mundo, fato empírica e materialmente possível a partir da exploração da América Latina. Nesse contexto a filosofia torna-se também um modo de justificar tal hegemonia. Daí não ser mera coincidência que os filósofos tidos como os mais significativos, ou clássicos, da história da filosofia moderna situem-se nos países de maior 
desenvolvimento econômico e/ou poderio político europeu. Se se parte, portanto, de uma perspectiva mundial da modernidade, a sequência histórica altera-se, conforme se nota no esquema seguinte. Aí não existe a linearidade do esquema anterior, uma vez que a Europa não é considerada como meta do desenvolvimento. Além disso, os caminhos entre a chamada Antiguidade clássica e a Europa Moderna são mais sinuosos, passam por outras regiões do mundo e indicam um amálgama de processos mais complexos.

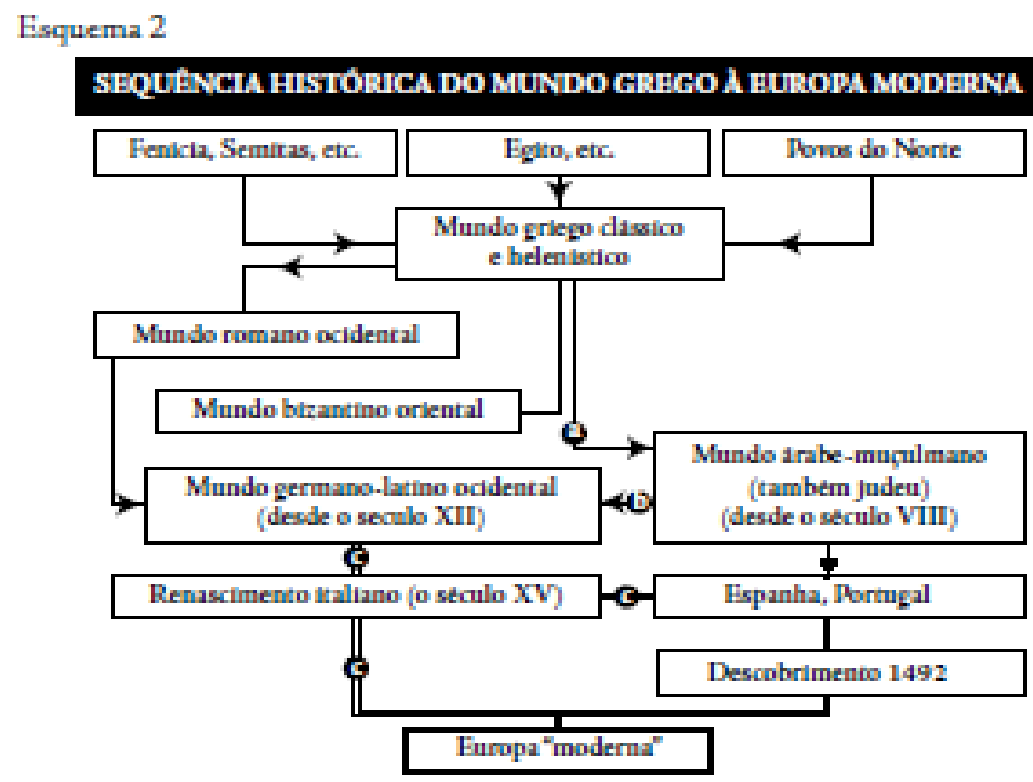

O Esquema 2 indica como a constituição da Europa moderna envolve dois movimentos inter-relacionados. Se focarmos no final do esquema, perceberemos uma linha de eventos históricos que desemboca no Renascimento italiano (o lado luminoso, segundo Mignolo, e que corresponde basicamente à lista de filósofos da Figura 3) e outra que destaca o mundo Ibero-americano (o lado obscuro, sem representantes filosóficos de acordo com as fontes pesquisadas). Com esse esquema, construído a partir da dinâmica histórica concreta, isto é, da expansão econômica, política e militar europeia, Dussel ressalta a importância de Espanha e Portugal, uma vez que foram as nações colonialistas inauguradoras de uma história mundial. Esse fato ocorrido no final do século XV e consolidado no XVI, contudo, não teve implicações apenas materiais. Na visão do filósofo, há toda uma reflexão filosófica que se interroga pela legitimidade ou não da 
conquista, pondo em discussão os aspectos éticos e políticos aí presentes (o escravismo colonial, o domínio sobre territórios estrangeiros, a natureza do outro - índio, negro) que serão ignorados pela narrativa habitual da história da filosofia. Esta fora construída nos séculos XVIII e XIX, isto é, em um momento posterior da expansão europeia quando a hegemonia ibérica havia sido substituída, nos séculos XVII e XVIII, por outros impérios coloniais (Holanda, França, Inglaterra) ${ }^{10}$. Nesse momento, uma construção teórica poderosa surge justificando e conferindo os contornos da história da filosofia tradicional. Expressão maior disso é a história hegeliana da filosofia, ancorada numa filosofia da história que narra o desenvolvimento da liberdade do espírito no mundo. A importância da teoria filosófica hegeliana não pode ser negligenciada. Seu impacto fez-se notar em seu tempo e permanece, implícita ou explicitamente, nas principais demarcações históricas e geográficas da filosofia. A história hegeliana da filosofia é a expressão mais elaborada do idealismo alemão que foi, conforme RABOSSI (2008), responsável por reformular ou mesmo instituir, o modo como, ainda hoje, se concebe, pratica e avalia a filosofia. A profunda influência do idealismo na configuração da universidade moderna, em especial no ensino de filosofia, deve, então, ser analisada para que se tenha um melhor entendimento dos problemas historiográficos da filosofia.

\section{Filosofia Moderna, colonialidade do saber e eurocentrismo: o exemplo de Hegel}

Começarei a análise com o exemplo de Hegel para depois entrar nas considerações mais gerais acerca do impacto do idealismo. Ao explorar a concepção hegeliana de história da filosofia, com foco em suas periodizações e seleções de temas e autores, notaremos o quanto o autor alemão reverbera nos dias atuais. Observemos os passos do pensamento filosófico, as referências históricas e a geografia da razão presentes nas

\footnotetext{
${ }^{10} \mathrm{O}$ detalhamento histórico e conceitual dessa mudança não caberia nos limites deste ensaio. Remeto leitoras e leitores aos principais textos de DUSSEL (2005, 2007 e 2014).
}

Filos. e Educ., Campinas, SP, v.10, n.1, p.90-120, jan./abr. 2018 - ISSN 1984-9605 
Lições sobre a História da Filosofia ${ }^{11}$. Na Introdução ${ }^{12}$, quando apresenta a divisão da história da filosofia, Hegel afirma:

A história da filosofia divide-se, portanto, nos três períodos da filosofia grega, da filosofia do tempo intermédio e da filosofia do tempo moderno; o primeiro destes períodos é determinado pelo pensamento em geral, o segundo cinde-se no contraste da essência com a reflexão formal, ao passo que o terceiro tem por base o conceito.[...].

Primeiro período. Começa nos tempos de Tales, cerca do ano $600 \mathrm{a}$. C. e estende-se até ao apogeu da filosofia neoplatônica com Plotino, no século III d. C. e sua ulterior continuação e evolução por meio de Proclo, no século $\mathrm{V}$, até a extinção de toda a filosofia. A filosofia neoplatônica penetrou mais tarde no cristianismo, e muitas filosofias dentro do cristianismo não têm outra base além desta. Temos aqui um período de pouco mais ou menos mil anos, cujo fim coincide com as emigrações de povos e com a queda do Império Romano.

Segundo período. É o da Idade Média, o dos autores escolásticos. Historicamente merecem também ser mencionados os árabes e os judeus. Mas esta filosofia desenvolve-se principalmente dentro da Igreja cristã: período que abarca pouco mais dum milênio.

Terceiro período. A filosofia dos tempos modernos consolidou-se apenas ao tempo da Guerra dos Trinta Anos [1618-1648], com Bacon, com Jacob Boehme e com Descartes, o qual começa com a distinção contida no Cogito, ergo sum. Este período cronologicamente compreende ainda poucos séculos e, por isso, esta filosofia é todavia algo de novo (2000, p. 392-3).

Se sobrepusermos essa periodização geral ao Esquema 1 de Dussel verificaremos como Hegel ilustra a visão eurocêntrica da história. Os filósofos e correntes citados pelo filósofo alemão se encaixam nos blocos históricos indicados pelo filósofo latino-americano. A título de exemplo:

Mundo Grego => Tales

Mundo Romano pagão e cristão => Plotino e Proclo

Mundo cristão medieval $=>$ Escolásticos

Mundo Europeu moderno => Bacon, Boehme, Descartes

\footnotetext{
${ }^{11}$ Faço uso das publicações brasileira (que traduz apenas a introdução) e mexicana (texto completo), ambas baseadas na edição de Michelet.

${ }^{12}$ Lembro também do germanocentrismo do filósofo que concebe, ao fim, duas filosofias acabadas, a grega e a alemã (cf. Hegel, 2000, p. 392). O tema do nacionalismo filosófico mereceria uma abordagem mais detida na história da filosofia, que costuma negligenciar as declarações chauvinistas dos clássicos e dos contemporâneos, cf. o exemplo de Heidegger (2000 e 2009) quando atribui, sem maiores explicações, um valor ontológico superior às línguas grega e alemã.
} 
Do contrário, se aplicarmos as referências hegelianas ao Esquema 2 de Dussel vários espaços ficariam vazios, por exemplo, o "Mundo bizantino oriental" ou "Espanha, Portugal". Como o tema deste ensaio se restringe ao período moderno, não explorarei os períodos históricos Antigo e Medieval.

Os eventos que precedem a filosofia moderna e os principais autores do período são retomados ulteriormente na obra hegeliana ${ }^{13}$. O Renascimento e a Reforma comparecem como momentos fundamentais. Uma plêiade de autores são citados, sem que se esmiúce cada uma de suas ideias. De toda forma, alguns nomes são destacados: Cardano, G. Bruno, Vanini, Campanella, Petrus Ramus ${ }^{14}$. Outros, como Montaigne e Maquiavel, são lembrados como pensadores interessantes, reconhecidos em seu valor para o campo filosófico ainda que, na perspectiva de Hegel, pertençam mais ao panorama geral da cultura que à filosofia em sentido estrito (cf. Hegel, 1985, p. 191).

Com relação ao período Moderno, uma série de filósofos são discutidos. Além dos já indicados acima, comparecem: Spinoza, Malebranche, Hobbes, Locke, Hume, Berkeley, Grocio, Pufendorf, Newton, Leibniz, Wolff, Reid, Montesquieu, Helvetius, Rousseau, Jacobi, Kant, Fichte, Schelling. Esta lista não é exaustiva, outros nomes são lembrados (cf. Hegel, 1997, p. 203-520). O conjunto de autores está organizado nas seguintes orientações filosóficas: racionalismo, empirismo, ceticismo, idealismo, Ilustração.

O que se percebe nesse elenco hegeliano é que seus representantes encaixam-se nas fronteiras apontadas na Figura 1 (mapa-múndi), sendo dada ênfase às filosofias francesa, britânica e alemã no período moderno. Os temas e correntes, assim como os locais de produção filosófica, condizem com as bases assinaladas nas Figuras 2 (lista de filósofos da modernidade) e 3 (temas e correntes). Na visão hegeliana, contudo, o desdobramento da razão na história, cuja forma ideal transparece no desenvolvimento da

\footnotetext{
${ }^{13} \mathrm{O}$ tomo III da tradução espanhola das Lições contém o encerramento do primeiro e as apresentações do segundo e terceiro períodos indicados pelo filósofo. Não existe tradução em português.

${ }^{14}$ Cf. esses e outros pensadores em HEGEL (1985, p. 166-192).
} 
filosofia, não possui um significado condicionado temporalmente, mas antes um significado histórico-absoluto. Para o filósofo alemão, portanto, se a história da filosofia revela uma história da razão na Europa, isto quer dizer simplesmente que o curso histórico filosófico europeu corresponde ao curso histórico da filosofia enquanto tal. Em Hegel temos, então, algo muito curioso. Por um lado, uma valorização da história na filosofia como nunca nenhum sistema filosófico havia realizado. Não se compreende o absoluto fora da história. Por outro, essa história, que é a história da razão em sua expressão mais acabada, serve à justificação do eurocentrismo na filosofia. Desse modo, Hegel, tal como um cartógrafo, elabora o mapa da razão filosófica. Sair de suas coordenadas significa percorrer outros mapas que não o filosófico. O desvio é perigoso; corre-se o risco de pegar outros caminhos (para Hegel, da ciência, da religião, da filosofia popular; para os acadêmicos de hoje, do ensaísmo, da história geral das ideias). O percurso está traçado, os pontos de apoio do pensamento (isto é, os representantes da razão) estão estabelecidos. Porém, esse mapa não deixa muita terra por ser conhecida? O roteiro do pensamento hegeliano, ao coincidir com as rotas do poder na modernidade, não deixa de revelar uma lógica colonial do saber, como se depreende do modelo interpretativo moderno/colonial. E se contextualizarmos o sistema hegeliano isso fica mais evidente. É justamente no século XIX que a Europa conseguirá se impor - graças à revolução industrial - econômica, técnica, militar e politicamente em todo mundo, inaugurando uma nova fase do colonialismo ao avançar sobre a Ásia e o interior da África. Esse avanço se concretiza pela força mas também pelas ideias. O progresso material propalado vem acompanhado de um discurso civilizatório. Uma gama de conhecimentos deverão atestar a superioridade europeia verificada no mundo material e político. A filosofia insere-se nesse conjunto de saberes.

Mas podemos nos perguntar se a compreensão hegeliana da história da filosofia já não estaria a muito superada, dada as críticas realizadas tanto pelos seus oponentes imediatos quanto pelos filósofos contemporâneos. Colocaria em suspeita essa pretensa superação. Afirmaria com LÖWITH 
(cf. 2014, p. 42) que a consciência histórica da filosofia hegeliana formou não só os seus discípulos e sucessores, mas também seus adversários. Talvez nem Marx ou Nietzsche, nem mesmo Russell ou Deleuze, para ficar em confessos adversários do hegelianismo, tenham conseguido escapar da "cartografia da razão filosófica" desenhada por Hegel. Diria que os "mapas da razão" pressupostos por esses e outros filósofos, incluindo seus seguidores, terminam por percorrer os circuitos hegelianos, ainda que resolvam, vez ou outra, se deter mais num ponto, detalhar determinada região filosófica, valorizar algum aspecto negligenciado. No final das contas, para usar uma imagem, os ecossistemas visitados são invariantes, poucos se aventuram, por exemplo, em terras tropicais ou atravessam os Pirineus.

Em Hegel, a história da filosofia torna-se uma iniciação necessária ao próprio conhecimento da filosofia. Essa exigência levou o filósofo a iniciativas institucionais importantes como, a oferta de um curso de história da filosofia (foram 9 entre os anos de 1805 e 1830, nas Universidades de Jena, Heidelberg e Berlim) e a defesa da "história da filosofia" no rol de matérias a serem ensinadas na universidade ${ }^{15}$. Mas a valorização da história presente em Hegel não se restringe a uma idiossincrasia do filósofo, está ligada a uma nova concepção de filosofia originada no idealismo alemão e que se consolidou como modo corrente do ensino filosófico.

\section{O Cânon e a história oficial}

A concepção segundo a qual a filosofia possui uma tradição própria de pensamento e uma relação diferenciada com este passado é algo comum. Presente em documentos oficiais ${ }^{16}$, na literatura da área ${ }^{17}$ e nos

\footnotetext{
${ }^{15}$ Sobre isso cf. a Carta ao real Conselheiro do Governo prussiano e Professor Friedrich Rayner, de 1816 in HEGEL (s/d).

${ }^{16}$ Conforme as Orientações curriculares para o ensino médio: Filosofia: "Neste ponto, em que se procura a confluência entre a especificidade da Filosofia e seu papel formador no ensino médio, cabe enfatizar um aspecto peculiar que a diferencia de outras áreas do saber: a relação singular que a Filosofia mantém com sua história, sempre retornando a seus textos clássicos para descobrir sua identidade, mas também sua atualidade e sentido" (BRASIL, Secretaria de Educação Básica, 2006, p. 27, grifo meu). Já as Diretrizes Curriculares para os Cursos de Graduação em Filosofia, no item "Perfil dos Formandos", apontam: "Sólida formação de história da filosofia, que capacite para a compreensão e a
} 
desenhos curriculares ${ }^{18}$ tal noção não costuma ser questionada. Isso está longe de ser um acaso, pelo menos segundo Eduardo Rabossi, que desenvolve instigantes reflexões sobre o tema na obra En el comienzo Dios creó el Canon (2008).

Rabossi está interessado em compreender como se pratica a filosofia, e deixa de lado a definição geral do que seja a filosofia ${ }^{19}$. Ele se propõe a "mostrar que o discurso tradicional sobre a filosofia disfarça ou ignora os traços constitutivos de sua prática efetiva" (2008, p. 212). Nessa investigação, o autor se dedica à inscrição institucional da filosofia, revelando que a) aquilo que temos concebido, praticado e avaliado como filosofia é uma disciplina jovem, com cerca de duzentos anos; b) que a longa tradição atribuída à filosofia não passa de um relato histórico construído também há duzentos anos; c) que a filosofia, enquanto disciplina, é anômala, apresentando controvérsias de sentidos ou conteúdos não condizentes com sua presunção cognitiva. Essas afirmações contradizem o senso comum filosófico e podem parecer descabidas, afinal, um dos orgulhos da filosofia é justamente sua longa tradição, cujas raízes se estenderiam até a Antiguidade Grega Arcaica. Aqui não reconstituirei os passos argumentativos de Rabossi que fundamentariam cada uma das afirmações indicadas. Interessa para meu propósito parte de suas

transmissão dos principais temas, problemas, sistemas filosóficos, assim como para a análise e reflexão crítica da realidade social em que se insere” (BRASIL, MEC, 2001, p. 3, grifo meu).

${ }^{17}$ Ilustrativa é a posição de Franklin LEOPOLDO E SILVA, em texto que se tornou referência para o ensino de filosofia no país: “[...] a filosofia é, de alguma maneira, a sua história, na medida em que os conceitos forjados numa determinada época, herdados e transfigurados pela posteridade, não podem ser entendidos como aquisições no curso de um desenvolvimento científico, mas sucessivas retomadas, que somente podem ser compreendidas se devidamente contextualizadas em cada sistema ou em cada autor" (1986, p. 154, grifo meu).

${ }^{18}$ A título de exemplo, o Projeto Pedagógico do Curso de Licenciatura em Filosofia da UFRGS afirma no tópico "Perfil do Curso": "Ora, como a Filosofia não apresenta um corpo canônico de conhecimentos (doutrina, método e conceitos), a sua unidade lhe é emprestada pelo diálogo com sua tradição. Assim, é de fundamental importância que o aluno adquira certa familiaridade com as obras clássicas da Filosofia e, mais ainda, seja capaz de se apropriar, de maneira reflexiva e crítica, desses textos" (UFRGS, 2013, p. 1, grifo meu).

${ }^{19}$ Como afirma: "Ao não existir uma caracterização compartilhada [de filosofia], senão muitas respostas alternativas, ao carecer-se de um metro com o qual medir sua adequação, as disputas acerca da natureza da filosofia são indecidíveis" (RABOSSI, 2008, p. 212, todas as traduções são minhas). 
observações acerca da condição institucional da filosofia, quer dizer, da filosofia tal como compreendida, trabalhada e apreciada nas academias e escolas.

Para Rabossi, a filosofia que exercemos tem suas origens nas inovações institucionais ocorridas no começo do século XIX na universidade alemã. $\mathrm{O}$ modelo universitário alemão, pouco a pouco, espalhou-se pelo mundo, sendo sua vigência hoje ecumênica. Naquela altura a universidade passava por uma mudança radical em seu projeto, formulando o que viria a ser conhecido como a universidade moderna. Nascida das reformas humboltianas e sob inspiração do idealismo, a reforma universitária criou uma instituição de caráter secular, dedicada exclusivamente à investigação e ao ensino de excelência, apoiada pelo Estado e gerida por regimentos próprios. Os professores passaram a gozar da liberdade de ensino e os estudantes puderam cursar distintas especialidades que conferiam uma habilitação profissional. No que se refere especificamente à filosofia, as alterações foram significativas.

As principais mudanças podem ser assim resumidas. $\mathrm{O}$ estatuto da faculdade de filosofia se modifica. Isso se verifica não só no nome - da antiga Faculdade de Artes para Faculdade de Filosofia - mas sobretudo na importância que é conferida ao conhecimento filosófico pelos reformadores alemães. De matéria propedêutica destinada à preparação para os estudos das faculdades superiores (direito, medicina e teologia), a filosofia passa ao estatuto de ciência superior, fundamentadora do conhecimento científico, reivindicando o uso livre da razão na busca da verdade.

Nesse contexto, um conjunto de obras defende a filosofia como disciplina secular, autônoma, técnica e rigorosa, e sua importância para a reforma universitária. Exemplos disso são: O conflito das faculdades, de Kant; as Lições sobre o método de estudos acadêmicos, de Schelling; os Discursos à nação alemã, de Fichte e mesmo os informes pedagógicos de Hegel $^{20}$. Esses e outros filósofos postulam um novo regime para a filosofia e participam - como reitores, conselheiros, professores - na implementação

\footnotetext{
${ }^{20}$ Cf. nota 14 .
} 
da reforma. Atribuem um papel original à filosofia e logram ter suas ideias assumidas pelas faculdades de filosofia, ganhando assim prestígio institucional. A institucionalização da filosofia conseguida nesse período mais que uma vitória administrativa, ocupando novos espaços universitários, no entendimento de Rabossi, moldou uma maneira de praticar a filosofia ${ }^{21}$.

Ainda que o idealismo, a doutrina filosófica que embasou a reforma, tenha posteriormente sucumbido, deixou um legado disciplinar. Isto é, uma determinada concepção e prática profissional que se tornaram fatores constitutivos do modo como concebemos, praticamos e avaliamos o que se chama "fillosofia". O idealismo, assim, como que estabeleceu o padrão e os requisitos fundamentais para o exercício profissional e disciplinar da filosofia. Nos termos de Rabossi, essa doutrina criou um Cânon que

\begin{abstract}
“[...] consagrou a autonomia da filosofia e seu caráter secular, identificou os valores cognoscitivos e práticos que deve defender, afirmou o caráter universal e necessário do conhecimento filosófico, indicou àqueles que filosofam a tarefa de ser guardiães da racionalidade, insistiu na supremacia cognoscitiva do saber filosófico e lhe atribuiu, ademais, uma história própria" (2008, p. 50 , grifo meu).
\end{abstract}

A concepção disciplinar da filosofia herdada do idealismo ultrapassa a doutrina, isto é, seus conteúdos filosóficos. O que se mantém é um compêndio das condições de exercício legítimo da profissão filosófica. Determinados preceitos fixam os limites, caracterizam e definem o que é ou não filosofia. Rabossi enumera dez $\operatorname{preceitos}^{22}$, neste trabalho, basta assinalar três.

1) "A filosofia tem um domínio próprio, distinto e excludente dos domínios próprios de outras disciplinas e faz uso de um conjunto de termos técnicos formais, distintos e excludentes da terminologia específica de outras disciplinas" (2008, p. 74).

2) "Os problemas que preocupam os filósofos afloram em distintos âmbitos: o sentido comum, a vida, a linguagem, as ciências, as

\footnotetext{
${ }^{21}$ Para outras dimensões desse processo na Alemanha do século XIX, cf. o capítulo 2 de RABOSSI (2008).

${ }^{22}$ Cf. os demais preceitos em RABOSSI (2008, p. 74-6).
} 
religiões, a literatura, a política, a história, a arte, a sociedade, as próprias doutrinas filosóficas, mas todos confluem, cedo ou tarde, para algum(uns) dos grandes problemas filosóficos tradicionais, que são perenes” (2008, p. 74).

3) “A filosofia tem um relação especial com seu passado. Nas disciplinas correntes esta relação é contingente: sua prática não requer de maneira essencial o conhecimento da história correspondente; a filosofia é um caso excepcional: seu passado é uma parte integral dela" (2008, p. 76).

O Cânon, reforce-se, não é uma doutrina filosófica particular. As doutrinas são como os conteúdos teóricos possíveis condizentes com os preceitos do Cânon. Este funciona como marco regulatório, estabelece as condições básicas às quais devem se ajustar a filosofia e o filosofar, delimita o âmbito teórico lícito da filosofia: o que não responde aos preceitos não é filosofia.

Quero enfatizar mais uma vez a relação com a história e relacioná-la com as observações dos tópicos anteriores. Pensemos. Se a filosofia (e, por consequência, o filosofar) possui uma relação peculiar com sua tradição, que está constituída numa história oficial. Se esta, como procurei mostrar, tem um viés colonial e eurocêntrico. Conclui-se que a filosofia considerada lícita - e não uma pseudofilosofia - será aquela que se mostrar em diálogo com a história oficial e com os problemas perenes, clássicos da tradição. As iniciativas teóricas que fogem ao Cânon, seja porque dialogam com outras histórias, seja porque dedicam-se a problemas tidos como não tradicionais, são postas de lado, quando muito, consideradas importantes enquanto um pensamento geral, mas sem a dignidade filosófica. Dessa forma, problemas candentes da modernidade como o escravismo, a colonização, o racismo, ou outras correntes e pensadores diferentes dos fixados no Cânon, simplesmente não figuram ou têm um aparecimento episódico no ensino, nas pesquisas, nos currículos filosóficos.

Entretanto, como salienta Rabossi, a história da filosofia não tem porque ser identificada com a concepção imposta pela História Oficial - no 
caso particular deste texto, com a história da filosofia moderna tal como verificada em Hegel e nas fontes de pesquisa consultadas. Há outras maneiras de historiar a filosofia. Por exemplo, enfatizando o contexto cultural das produções filosóficas, as relações socioculturais de seus protagonistas, a relação da filosofia com a literatura, a política, etc.; ou ainda, produzindo uma história intelectual ou das mentalidades de uma época, considerando os filósofos como um tipo, entre outros, de intelectuais. Essas propostas, como admite o autor, apagariam as divisões, sempre discutíveis, entre filósofos maiores e menores, filósofos e não-filósofos, filosofia e não-filosofia. Contribuiriam, por outro lado, para questionar o pretenso caráter filosófico e quase exclusivo da história da filosofia - que muitas vezes toma como valoroso filosoficamente apenas o comentário de texto - e tende a prejudicar outras formas de reflexão que possibilitam desdobrar leituras possíveis do mundo atual no intuito de compreender como as coisas são e se relacionam entre si (cf. RABOSSI, 2008, p. 190 e 207). Tudo isso, convém salientar, não coloca um interdito ao conhecimento do passado, nem deslegitima o campo disciplinar "história da filosofia" ou o trabalho dos historiadores, mas serve de alerta para os prejuízos e - por que não dizer - os preconceitos que uma prática filosófica sustentada pelo Cânon pode conter. De minha parte, acrescentaria - e assim passaremos ao último tópico - uma tarefa importante a ser realizada para encarar os problemas historiográficos aqui discutidos é a reconstrução da história da filosofia moderna numa perspectiva descolonizadora.

Descolonizar a modernidade: apontamentos para uma outra historiografia

O modo como a modernidade aparece na história da filosofia só aparentemente é uma coisa óbvia. Quando olhada por um ângulo diferente a narrativa filosófica convencional apresenta cenários diversos. Nesse sentido, a observação de Serge Gruzinski sobre os profissionais da história mostra-se válida para os historiadores da filosofia: "Os trabalhos dos historiadores da Europa ocidental não nos ajudam a olhar para além dos limites dessa porção 
do mundo, e seus colegas americanos, ainda muitas vezes presos a fronteiras herdadas do século XIX, não nos trazem mais ar fresco” (2014, p. 41). As fronteiras geográficas da história da filosofia, como procurei apontar, também são construções do século XIX. O idealismo alemão, em especial Hegel, são seus grandes artífices.

Para sair dessas fronteiras, que são geográficas e epistêmicas, é necessário repensar a modernidade: sua história, sua geografia e seu conceito. Sem isso, o ensino de filosofia continuará a visitar os mesmos locais e a repetir os mesmos relatos. E pior, nunca entraremos - nós, habitantes de outra parte do mundo, no caso, da América Latina - nessa história. As experiências, as ideias, os temas, os problemas, os textos e os autores que poderiam nos interessar para compreendermos a nós mesmos, às nossas sociedades do passado e do presente, permanecerão esquecidos, ignorados.

Esse repensamento da modernidade leva a reconsiderar o papel dos países ibéricos. Gruzinski, por exemplo, lembra que:

[...] a modernidade dos ibéricos não se realiza no solo da Península, e não está, em absoluto, de acordo com a ideia que temos habitualmente da modernidade. Ela não toma o percurso obrigatório que corre direto da Itália para a França, a fim de atingir a Inglaterra e os países do norte, evitando uma Europa meridional, invariavelmente apreendida como arcaica e obscurantista ${ }^{23}$. Essa modernidade não passa tampouco pela construção do Estado-nação nem pela marcha em direção ao absolutismo cartesiano. Ela põe em jogo outros espaços, outras configurações políticas - a monarquia católica -, outros imaginários e, sobretudo, outros atores, que não são somente europeus, mas índios, como Chimalpahin, filipinos, japoneses, mulatos da África. Eis-nos longe das fronteiras da Europa ocidental" (2014, p. 95-6).

O historiador nos recorda que a modernidade, como processo de mundialização iniciado com a expansão e as conquistas ibéricas, envolve mobilidade de pessoas, mercadorias, horizontes e ideias conectando mundos e histórias. De tal forma que apresentar a história moderna desconsiderando

\footnotetext{
${ }^{23}$ Qualquer semelhança desse percurso com o percurso histórico do espírito em Hegel não é mera coincidência. A filosofia hegeliana da história (geral e filosófica) ainda paira no imaginário histórico ocidental.
} 
esses contatos, misturas e confrontos é cair em uma história provinciana, eurocêntrica.

A crítica do historiador conjuga-se com a crítica filosófica dos pensadores latino-americanos que buscam interpretar a história da filosofia moderna por meio da reconstrução das conexões entre a Europa e a América. Essa empreitada - com a qual procuro contribuir a partir do tema do ensino de filosofia -, desenrola-se através de três procedimentos. O primeiro é o da desconstrução da metanarrativa moderna e de sua geografia da razão, para isso faz-se necessária a crítica das formulações históricoconceituais eurocêntricas e de suas implicações para a noção de filosofia, para a pesquisa nos vários ramos do conhecimento filosófico (política, ética, estética, epistemologia, etc) e para o ensino de filosofia. Nessa tarefa é preciso estar atento às formulações clássicas e mais evidentemente eurocêntricas, como é o caso de Hegel, e mais ainda àquelas que supostamente fogem da cartografia hegeliana da razão, como pretendem as propostas pós-estruturalistas ou marxistas ${ }^{24}$. O segundo procedimento é o da ampliação das referências filosóficas, ou seja, a incorporação de outros textos, autores, temas e conceitos ao estudo do período moderno. Aqui as pesquisas realizadas pelo movimento latino-americano de história das $\operatorname{ideias}^{25}$ (com L. Zea, A. Ardao e A. Roig, para citar alguns), pelos historiadores do pensamento brasileiro (J. Cruz Costa, A. Paim, L. A. Cerqueira, P. Margutti, por exemplo) e dos próprios teóricos da decolonialidade e da filosofia da libertação são fundamentais. Isso porque esses estudos incluem Espanha, Portugal e América Latina na narrativa da Modernidade. Sendo assim, como afirma Dussel ao tratar da filosofia política,

“[...] então os filósofos espanhóis e portugueses (mesmo praticando uma filosofia de cunho escolástico, mas, por seu conteúdo, moderna) e os primeiros grandes pensadores latino-americanos do século XVI deveriam ser considerados como o início da filosofia da Modernidade" (2014, p. 15).

\footnotetext{
${ }^{24}$ Sobre o problema do eurocentrismo no pós-estruturalismo, cf. DUSSEL (1993). Com relação ao marxismo, cf. RESTREPO e ROJAS, (2010) e, de um ponto de vista marxista porém não-eurocentrado, cf. MARIÁTEGUI (2010) e o comentário de QUIJANO (1995).

${ }^{25}$ Sobre a história das ideias na América Latina, cf. CARVALHO (2009).
} 
O terceiro procedimento é uma decorrência dos dois anteriores: a reconstrução. Reconstruir os marcos e as caracterizações de períodos e correntes de pensamento levando-se em conta o nosso lugar no mundo, tanto no passado quanto no presente ${ }^{26}$. Isso implica um uso interessado da história que resgate momentos, obras, contextos, temas, conceitos negligenciados, até então encarados de maneira episódica ou simplesmente esquecidos, mas que contribuam para pensar o presente desde um horizonte histórico mais amplo e diversificado. O que não quer dizer um "vale tudo" historiográfico, uma vez que as reconstruções devem ser o mais possível rigorosas, passíveis de revisões, reformulações e refutações. Almeja-se a quebra de uma narrativa única não para impor uma nova metanarrativa também única, mas para pluralizar as narrativas sobre os mesmos acontecimentos e auxiliar no desvendamento das formas de dominação política, epistêmica, cultural.

A descolonização da modernidade no ensino de filosofia, nessa medida, é um contributo - certamente limitado - num processo maior de descolonização das mentes que nos permita vislumbrar as luzes e as sombras das histórias e dos projetos sob o signo da modernidade.

\section{Referências}

ARANHA, M. L.; MARTINS, M. H. Filosofando: introdução à filosofia. 5 ed. São Paulo: Moderna, 2013.

BRASIL, MEC. Parecer CNE/CES 492/2001 (Diretrizes Curriculares Nacionais dos cursos de Filosofia, História, Geografia, Serviço Social, Comunicação Social, Ciências Sociais, Letras, Biblioteconomia, Arquivologia e Museologia).

BRASIL, Secretaria de Educação Básica. Ciências humanas e suas tecnologias. Brasília: Ministério da Educação, Secretaria de Educação Básica, 2006. (Orientações curriculares para o ensino médio; volume 3)

\footnotetext{
${ }^{26}$ Os limites deste texto não me permitem entrar nas sugestões práticas da reconstrução. Para isso, remeto a leitora ou leitor para os esquemas históricos (que serão futuramente desenvolvidos) presentes no material de apoio de um minicurso que ofereci durante a $11^{\mathrm{a}}$ Semana de Educação da Unicamp e disponíveis em https://drive.google.com/open?id=0B2pdU2JQza8eZzR5VE5mSEo0VDA
} 
CARVAlHO, E. R. Pensadores da América Latina: o movimento latinoamericano de história das ideias. Goiânia: Editora UFG, 2009.

CERQUEIRA, L. A. Filosofia brasileira: ontogênese da consciência de si. Petrópolis: Vozes, 2002.

CRUZ COSTA, J. Contribuição à história das ideias no Brasil. Rio de Janeiro: Civilização Brasileira, 1967.

DUSSEL, E. 1492: O encobrimento do Outro. A origem do mito da modernidade. Petrópolis: Vozes, 1993.

DUSSEL, E. Ética da libertação: na idade da globalização e da exclusão. Trad. Ephraim Ferreira Alves, Jaime A. Clasen, Lucia M.E. Orth. 3. ed. Petrópolis: Vozes, 2007.

DUSSEL, E. Europa, modernidade e eurocentrismo. In: LANDER, E. (org.). A colonialidade do saber: eurocentrismo e ciências sociais. Buenos Aires: Clacso, 2005.

DUSSEL, E. Política da Libertação I: história mundial e crítica. Passo Fundo: IFIBE, 2014.

GALLO, S. Filosofia: experiência do pensamento. São Paulo: Scipione, 2013.

GRUZINSKI, S. As quatro partes do mundo: história de uma mundialização. Trad. Cleonice Paes Barreto Mourão; Consuelo Fortes Santiago. Belo Horizonte: Editora UFMG; São Paulo: Edusp, 2014.

HEGEL, G. W. F. Carta ao real Conselheiro do Governo prussiano e Professor Friedrich Rayner, de 1816. In: HEGEL, G. W. F. [Sobre o Ensino de Filosofia]. Trad. Artur Morão. Lusosofia:press, s/d. Disponível em: www.lusosofia.net. Acesso em: 27/01/2018.

HEGEL, G. W. F. Introdução à História da Filosofia. Trad. Antonio Pinto de Carvalho. São Paulo, SP: Nova Cultural, 2000. (Coleção Os Pensadores).

HEGEL, G. W. F. Lecciones sobre la historia de la filosofia. Trad. Elsa Cecilia Frost. México, D.F: Fondo de Cultura Económica,1985, vols. I e III.

HEIDEGGER, M. “Já só um Deus nos pode ainda salvar”. [Entrevista a revista alemã Der Spiegel em 23 de Setembro de 1966 e publicada no no 23/1976]. Tradução e notas de Irene Borges-Duarte. Universidade da Beira Interior Covilhã: Lusosofia:press, 2009. Disponível em:

http://www.lusosofia.net/textos/heideggger ja so um deus nos pode aind a salvar der spiegel.pdf. Acesso em: 01/02/2018.

HEIDEGGER, M. O que é isto - a filosofia? Trad. Ernildo Stein. São Paulo, SP: Nova Cultural, 2000. (Coleção Os Pensadores). 
LEOPOLDO E SILVA, F. História da filosofia: centro ou referencial? In: NETO, H. N.(Org.). O ensino de filosofia no $2^{\circ}$ grau. São Paulo: SOFIA: SEAF, 1986. p. 153-162.

LÖWITH, K. De Hegel a Nietzsche: a ruptura revolucionária no pensamento do século XIX: Marx e Kierkegaard. Trad. Flamarion Caldeira Ramos. Luiz Fernando Barrère Martin: São Paulo: Editora Unnesp, 2014.

MARIÁTEGUI, J. C. Sete ensaios de interpretação da realidade peruana. $2^{a}$ Ed. Trad. Felipe José Lindoso. São Paulo: Expressão Popular, 2010.

MARGUTTI, P. História da Filosofia do Brasil: o período Colonial (15001822). São Paulo: Loyola, 2013.

MIGNOLO, W. La idea de América Latina: la herida colonial y la opción decolonial. Barcelona: Gedisa Editorial, 2007.

PAIM, A. História das ideias filosóficas no Brasil. 5 ed. Londrina: Editora da UEL, 1997.

QUIJANO, A. Colonialidade do poder e classificação social. In: SANTOS, B.; MENESES, P. (orgs.). Epistemologias do Sul. São Paulo: Cortez, 2010.

QUIJANO, A. El marxismo en Mariátegui: una propuesta de racionalidad alternativa. In: SOBREVILLA ALCÁZAR, David (ed.). El marxismo de José Carlos Mariátegui - V Congreso Nacional de Filosofía: seminario realizado el 2 de agosto de 1994. Lima: Universidade de Lima; Amauta, 1995.

RABOSSI, E. En el comienzo Dios creó el Canon: Biblia berolinensis. Buenos Aires: Gedisa, 2008.

RESTREPO, E.; ROJAS, A. Inflexión Decolonial: fuentes, conceptos, cuestionamientos. Popayan: Editorial Universidad del Cauca, 2010.

Sites consultados: projetos pedagógicos de curso, currículos e índices universitários

INEP. Conceito Preliminar de Curso. Disponível em: http://portal.inep.gov.br/conceito-preliminar-de-curso-cpc-. Acesso em 23/01/2018.

PUC-Rio. Currículo Licenciatura. Disponível em: http://www.pucrio.br/ensinopesq/ccg/filosofia.html. Acesso em: 25/01/2018.

QS World University Rankings. Disponível em: https://www.topuniversities.com/university-rankings/university-subjectrankings/2017/philosophy. Acesso em 23/01/2018. 
UFBA. Grade Curricular Filosofia. Disponível em:

https://blog.ufba.br/dpfilo/os-cursos/. Acesso em: 25/01/2018.

UFBA. Projeto Pedagógico do Curso de Bacharelado e Licenciatura em Filosofia. Disponível em: https://blog.ufba.br/dpfilo/os-cursos/. Acesso em: 25/01/2018.

UFMG. Currículo Padrão Licenciatura em Filosofia. Disponível em: https://filosofia.fafich.ufmg.br/graduacao/curriculo-padrao/. Acesso em: 25/01/2018.

UFMG. Programas de disciplinas do curso de Filosofia. Disponível em: http://www.fafich.ufmg.br/atendimento/filosofia/programas-de-disciplinas Acesso em: 25/01/2018.

UFRGS. Projeto Pedagógico do Curso de Licenciatura em Filosofia. 2013. Disponível em:

https://www.ufrgs.br/filosofia/graduacao/licenciatura/projeto-licenciatura/. Acesso em: 25/01/2018.

UFRJ. Programas de disciplinas do curso de Filosofia. Disponível em: https://ifcs.ufri.br/index.php/departamentos/filosofia/programas. Acesso em: $25 / 01 / 2018$.

UFSC. Currículo Graduação em Filosofia. Disponível em: http://filosofia.ufsc.br/curriculo/. Acesso em: 25/01/2018.

UFSC. Projeto Político-Pedagógico da Graduação em Filosofia. 2004. Disponível em: http:// filosofia.ufsc.br/projeto-politico-pedagogico/. Acesso em: 25/01/2018.

UNICAMP. Programa das disciplinas do curso de Filosofia. Disponível em: https://www.ifch.unicamp.br/ifch/graduacao/disciplinas. Acesso em: 25/01/2018.

UNICAMP. Projeto Pedagógico da Graduação em Filosofia. Disponível em: https://www.ifch.unicamp.br/pf-ifch/public-files/graduacao/projetopedagogico-filosofia.pdf. Acesso em: 25/01/2018.

UNIFRA. Projeto Pedagógico do Curso de Filosofia. 2017. Disponível em: http://wwww.unifra.br/site/pagina/conteudo/33. Acesso em: 25/01/2018.

USP. Projeto Pedagógico do Curso de Filosofia. 2012-2016. Disponível em: http://www.filosofia.fflch.usp.br/departamento/projetoacademico. Acesso em: 25/01/2018. 